\title{
Humic Acid Formation in Artificial Soils Amended with Compost at Different Stages of Organic Matter Evolution
}

\author{
Fabrizio Adani* and M. Spagnol DiProVe-Università di Milano
}

A composting process was conducted under optimal conditions for $150 \mathrm{~d}$, obtaining three biomasses at different levels of maturity: raw material (RM), fresh compost obtained after $11 \mathrm{~d}$ of composting (FC), and evolved compost (EC) obtained after $150 \mathrm{~d}$ of composting. During the composting process, HAs were extracted and fully characterized by mass balance, DRIFT, and $1 \mathrm{H}$ and $13 \mathrm{C}$-nuclear magnetic resonance spectroscopy. Each compost sample was incubated for $180 \mathrm{~d}$ in an artificial soil, after which HA extraction was repeated and characterized. To compare composts containing different amounts of labile organic matter (OM), an equal amount of unhydrolyzable OM was added to the soils. Our results indicated that compost HAs consist of a biologically and chemically stable fraction (i.e., the unhydrolyzable HA [U-HA]) and a labile fraction, whose relative contents depended on the composting duration. Humic acid from more EC contained a higher amount of recalcitrant fraction (aromatic carbon) and a lesser amount of labile fraction (aliphatic carbon) than HA from RM and FC. These results suggest that the humification process during composting preserves the more recalcitrant fraction of the compost-alkali soluble/acid insoluble fraction (HA-fraction). Incubation of composts in soil showed that due to the higher labile fraction content, HAs from raw material were more degraded than those from EC. The abundance of labile carbon of soil amended with less-evolved compost (RM and FC) allowed the more recalcitrant fractions of U-HA to be more preserved than in EC. These results suggest that lessevolved compost could contribute more than well evolved compost to the stable soil OM. $S_{\text {quantity, quality, and dynamics (Lal, 2000). Up to } 70 \text { to }}^{\text {oll quality depends on the soil oranic matter }}$ $80 \%$ of SOM in mineral soil is composed of humic substances (HS) (Piccolo, 2002). Compost can be beneficial for soil because it improves soil properties and contributes to the soil humus balance (Giusquiani et al., 1995; Quèdraogo et al., 2001; Leifeld et al., 2002). The definition of HS is only used for operational purposes because it is based on the solubility in the aqueous solutions used as extractants (Piccolo, 2002), and the term humic acid (HA) is used to indicate the HS soluble in dilute alkali but insoluble in dilute acid $(\mathrm{pH}<1)$ (Piccolo, 2002). Humic acid is a negatively charged colloid, is recalcitrant to biodegradation, and can be stored in soil for long periods (Qualls, 2004). Because of these properties, HA plays an important role in determining soil characteristics by influencing its chemical, physical, and biological properties. Consequently, compost HA is considered an indicator of the ability of compost to contribute to SOM balance (Adani et al., 2006a).

Humification during composting has been the subject of extensive study (Sugahara and Inoko, 1981; Inbar et al., 1990; Chen and Inbar, 1993; Chefetz et al., 1999; Genevini et al., 2002a). However, the nature of the humification process during composting remains unclear. Furthermore, the end products of compost humification differ from those of soils (González-Vila et al., 1999; Almendros et al., 2000).

It was previously reported that $\mathrm{HA}$ is formed ex novo during composting (Chen and Inbar, 1993). This report was based on the findings that the relative content of the HA fraction increased during composting. This interpretation of the humification process refers to the classical route of HA formation, which hypothesizes that bio-macromolecules are broken up into small constituents and then recombined to form chemically complex "geopolymers" (Senesi and Loffredo, 1999). However, when considering the absolute content of HA, there is evidence that during composting this content does not increase notably (Adani et al., 1999; González-Vila et al., 1999).

More recently, it was shown that humification during the composting process should be interpreted as the concentrating

DiProVe-Università di Milano, via Celoria 2, 20133 Milano, Italy.

Abbreviations: DRI, dynamic respiration index; EC, evolved compost; FAC, fulvic acid carbon; $F C$, fresh compost; $\mathrm{HA}$, humic acid; $\mathrm{HAC}$, humic acid carbon; HS, humic substance; HUC, humic carbon; NHC, nonhumified carbon; OM, organic matter; RM, raw material; SEC, soil amended with evolved compost; SFC, soil amended with fresh compost; TEC, total extractable carbon; TOC, total organic carbon; U-TOC, unhydrolyzable total organic carbon. 
of pre-existing nonhydrolyzable HA molecules (proto-HA) (Chefetz et al., 1999; Genevini et al., 2002a, b). Also, during composting, modifications of nonhydrolyzable HA, such as decarboxylation, demethoxylation, and a general removal of O-alkyl and alkyl carbons, occur (González-Vila et al., 1999; Chefetz et al., 1999; Genevini et al., 2002a).

This view of the humification process does not conflict with more recent studies on the nature of humic substances that indicate that HA is composed of low-molecular-weight hydrophobic and amphiphilic compounds (lignin, polysaccharides, lipids, and peptides) derived from the degradation and decomposition of dead biological material, arranged in supramolecular structures (Piccolo, 2002; Simpson, 2002; Sutton and Sposito, 2005). Therefore, based on our previous work (Genevini et al., 2002a, 2002b; Chefetz et al., 1999; Adani et al., 2006b) and taking into consideration the new interpretation of the HA structure, it can be concluded that compost HAs are represented by a mix of low-molecular-weight molecules structured in a supramolecular association and whose composition depends on the duration of the degradation processes (the composting process removes more labile fraction).

The production of fresh compost by high-rate composting - compost produced without the curing phase-represents a new trend in composting (Scaglia et al., 2000). This composting strategy was devised to reduce composting time and produce a hygienic, stable, and safe product.

It can be argued that if humification of OM takes place during the curing phase (Chen and Inbar, 1993), then the humus content of fresh compost is limited compared with mature compost. However, if humification is considered as the conservation and modification of more recalcitrant biomolecules, then the differences in the contribution to the soil-humus balance depend only on the relative concentration of these molecules.

The aim of this work was to study the effects of the composting process on the concentration and preservation of pre-existing HA (nonhydrolyzable HA) in compost. This study investigated the effects of compost, obtained at different degrees of evolution (fresh compost [FC] obtained after $11 \mathrm{~d}$ of composting and evolved compost [EC] obtained after 150 $\mathrm{d}$ of composting), on the quantity and quality of soil HA.

\section{Materials and Methods}

\section{Compost Preparation}

The raw material (RM) used was an organic mix consisting of municipal solid waste and green waste collected from the city of Milano (North Italy) mixed together in a ratio of 2.5:1 (wet weight) or 1:1 (dry weight). Raw material (RM) was composted in a laboratory adiabatic reactor (Adani et al., 2004). Fresh compost was obtained at the end of the high-rate composting phase (11 composting days) when compost attained the medium biological stability as required by the regional rules of Lombardia (North Italy) (Scaglia et al., 2000). This product was characterized by an oxygen uptake rate expressed as a dynamic respiration index (DRI) of $1000 \mathrm{mg} \mathrm{O}_{2} \mathrm{~kg}^{-1}$ organic matter $(\mathrm{OM})^{-1} \mathrm{~h}^{-1}$ (Adani et al., 2004). More $\mathrm{EC}$ was obtained after a total of 150 composting days (high-rate composting plus a curing phase). This product exhibited a DRI of $200 \mathrm{mg} \mathrm{O}_{2} \mathrm{~kg}$ $\mathrm{OM}^{-1} \mathrm{~h}^{-1}$, which was lower than the DRI that defines mature compost (500 $\mathrm{mg} \mathrm{O}_{2} \mathrm{~kg} \mathrm{OM}^{-1} \mathrm{~h}^{-1}$ ) (Adani et al., 2004).

All matrices (RM, FC, and EC) were sampled during composting, following procedures described by The U.S. Composting Council (1997). Samples were vacuum dried at $60^{\circ} \mathrm{C}$, ground to a $\varnothing<0.5 \mathrm{~mm}$, and stored for subsequent use.

\section{Incubation Test}

The soil used for the incubation tests was a sandy mineral substrate consisting of sand (particle size $\varnothing=0.5-0.8 \mathrm{~mm}, \mathrm{pH}$ 7) and clay (bentonite-montmorillonite-like mineral sieved at $\varnothing<1 \mathrm{~mm}, \mathrm{pH} 7, \mathrm{CEC}=6.5 \mathrm{cmol}^{+} \mathrm{kg}^{-1}$ ) (Adani and Ricca, 2004). Sand and clay were mixed in a ratio of $9: 1(w / w)$. An artificial medium was chosen to avoid contamination from SOM (Almendros and Dorado, 1999) and does not represent a natural soil (Adani and Ricca, 2004) and needs future comparison with natural soil. Organic amendments were added to the soil by normalizing each biomass to the nonhydrolyzable fraction of the total organic carbon (TOC) (see below for analytical details) and named the total unhydrolyzable carbon (U-TOC).

An equal amount of this fraction $\left(3 \mathrm{~g} \mathrm{~kg}^{-1} \mathrm{dm}^{-1}\right)$ was added to each sample amended with different composts. This choice was based on previous research (Adani and Ricca, 2004) indicating that the U-TOC was the stable OM fraction remaining after a medium-term degradation process $(6 \mathrm{mo})$. Moreover, the nonhydrolyzable OM fraction (the biochemically protected $\mathrm{OM}$ ) was shown to be the recalcitrant fraction that contributes, together with physically and chemically stabilized OM, to the stable soil OM (Six et al., 2002; Mikutta et al., 2006). Therefore, the ability of different organic matrices characterized by different carbon contents available to contribute to the stable OM of soil could be compared using this method.

Using 5-L pots, incubation tests were replicated twice for each sample. Each pot was filled with approximately $2.5 \mathrm{~kg}$ of soil (dry matter). Soils were wetted with water and kept at $60 \%(\mathrm{w} / \mathrm{w})$ of the maximum water-holding capacity. Water content was corrected gravimetrically every $3 \mathrm{~d}$. Pots were incubated for $180 \mathrm{~d}$ in a chamber at $26 \pm 2^{\circ} \mathrm{C}$ under dark conditions. During the incubation tests, soils amended with composts at different levels of maturity-SRM (soil amended with RM), soil amended with fresh compost (SFC), and soil amended with evolved compost (SEC)—were sampled at time 0 (T0), 60 (T2), 90 (T3), 120 (T4), and $180 \mathrm{~d}$ (T6), respectively. Each sample weighed approximately $100 \mathrm{~g}$, except for the last sample, which weighed 150 $\mathrm{g}$ and was formed by three subsamples taken from each replicate. Soils were vacuum-dried at $65^{\circ} \mathrm{C}$ and then used for analytical determination. Analyses were performed in triplicate.

\section{Organic Matter and Organic Carbon Fractionation}

The OM was fractionated into its macromolecules using the wood analysis method adapted for soil (Adani and Ricca, 2004). Three consecutive extractions were performed on soil samples. The fraction soluble in benzene/ethanol mixture $(2: 1 \mathrm{v} / \mathrm{v})$ and $16.87 \mathrm{~mol} \mathrm{~L}^{-1}$ ethanol (soluble lipids, waxes, soluble tannins, 
proteins, and part of fulvic acids) was solubilized by the first extraction step (fraction I); protein, hemicelluloses, and part of fulvic acids (fraction II) were solubilized in hot $0.94 \mathrm{~mol} \mathrm{~L}^{-1} \mathrm{H}_{2} \mathrm{SO}_{4}$ under reflux for $2 \mathrm{~h}$ (second step); and cellulose (fraction III) was solubilized in $13.50 \mathrm{~mol} \mathrm{~L}^{-1} \mathrm{H}_{2} \mathrm{SO}_{4}$ at $4^{\circ} \mathrm{C}$ for $24 \mathrm{~h}$ (third step). The lingo-humic complex (fraction IV), insoluble in any solvent, was left in the residual fraction (lingo-humic complex plus acidinsoluble ashes) and quantified by ignition at $650^{\circ} \mathrm{C}$ of an aliquot of this fraction.

Isolation of the ligno-humic complex was performed for RM, composts, and soils. Volatile solids and ash content for the three organic matrices were determined by ignition loss at $650^{\circ} \mathrm{C}$ (APHA, 1992).

Humic acid (HA) and unhydrolyzable humic acid (U-HA) extractions were performed as described previously. Humic acid was directly extracted from RM, compost, and soil samples, whereas UHA was extracted for RM, compost, and soil samples from the ligno-humic complex obtained as described previously.

In brief, $2 \mathrm{~g}$ of dried compost (10 $\mathrm{g}$ for soils) was extracted in a 250-mL Erlenmeyer flask with $100 \mathrm{~mL}$ of $0.1 \mathrm{~mol} \mathrm{~L}^{-1} \mathrm{NaOH}$ and $0.1 \mathrm{~mol} \mathrm{~L}^{-1} \mathrm{Na}_{4} \mathrm{P}_{2} \mathrm{O}_{7}$ solution at $65^{\circ} \mathrm{C}$ for $24 \mathrm{~h}$ under $\mathrm{N}_{2}$ in a Dubnoff thermostatic bath at 100 oscillations min $^{-1}$ (Adani and Ricca, 2004). The sample was cooled to room temperature in a $150-\mathrm{mL}$ centrifuge tube and centrifuged at 13,000 rpm for 20 min. The extraction was repeated by adding distillate water until the supernatant was clear. The supernatant solution (alkaline extract) (TE or U-TE) was filtered through a $0.45-\mu \mathrm{m}$ Millipore filter. The insoluble humic fraction (HU or U-HU) was retained and washed until a neutral $\mathrm{pH}$ was obtained and then stored. The alkaline extracts were then acidified to below pH 1.5 and centrifuged at $5000 \mathrm{rpm}$ for $20 \mathrm{~min}$. The insoluble fractions (HA or U-HA) were washed with distilled water until a neutral $\mathrm{pH}$ was obtained and followed by an extraction with $2.82 \mathrm{~mol} \mathrm{~L}^{-1} \mathrm{HF}$ for $24 \mathrm{~h}$ at room temperature to remove inorganic constituents (silicates). Then, HA (or U-HA) was washed to remove excess of $\mathrm{HF}$ with distilled water until a neutral $\mathrm{pH}$ was obtained, vacuum dried at $60^{\circ} \mathrm{C}$, and weighed. The ash content of all extracted fractions was less than $1 \%$. The residual alkali-soluble/acid-soluble fraction was purified by chromatography using a polyvinylpirrolidone column, obtaining two fractions: fulvic acid (FA) and nonhumified material (NH).

The alkali-soluble/acid-soluble fraction obtained starting from the lingo-humic fraction represented the U-NH, as purification by chromatography using a polyvinylpirrolidone was omitted because FA is solubilized during OM fractionation (see Fraction I and II).

All fractions obtained during the HA and U-HA extractions were quantified by organic carbon determinations (Ciavatta et al., 1990) obtaining total organic carbon (TOC), total extractable carbon (TEC), humic acid carbon (HAC), fulvic acid carbon (FAC), humin carbon (HUC), and corresponding unhydrolyzable-C. Nonhumified carbon (NHC) was calculated as [TEC - (FA + HA)] and U-NHC as (U-TEC - U-HA).

Variations in the content of each single fraction during composting and soil incubation were calculated from the start and end absolute fraction contents $(\mathrm{g})$ and reported as the relative increase or decrease $\left(\mathrm{g} \mathrm{kg}^{-1}\right)$.

\section{Diffuse Reflectance Infrared Fourier Transformed, ${ }^{1} \mathrm{H}$-Nuclear Magnetic Resonance, and ${ }^{13} \mathrm{C}-$ Nuclear Magnetic Resonance Spectroscopy}

Diffuse reflectance infrared fourier transformed (DRIFT) spectra were recorded with a FT/IR-300 E JASCO spectrometer equipped with a Diffuse Reflectance attachment (Pike Technologies, Inc, Madison, WI). The samples, a 7 -mg sample and 700 mg potassium bromide (FT grade; Aldrich Chemical Co, St. Louis, MO), were finely ground using a Wing-L-Bug agate ball mill for 10 min (Specamill-Greseby-Specac, Kent, UK). The spectra were acquired in the 4000 to $600 \mathrm{~cm}^{-1}$ range with $4 \mathrm{~cm}^{-1}$ resolution, and 100 scans were performed on each acquisition. A background spectrum of finely powdered potassium bromide was recorded using the same instrument settings. Peak assignments were made according to Adani and Ricca (2004). In brief, the bands at 2920 to $2850 \mathrm{~cm}^{-1}$ were attributed to aliphatic chains and peaks at $1710 \mathrm{~cm}^{-1}$ to the stretching of $\mathrm{C}=\mathrm{O}$ of ester, ketons, and acid carboxylic. Bands at $1666 \mathrm{~cm}^{-1}$ and $1542 \mathrm{~cm}^{-1}$ were attributed to the stretching of $\mathrm{C}=\mathrm{O}$ of amide (amide $\mathrm{I}$ ) and to deformation of $\mathrm{N}-\mathrm{H}$ bond and stretching of $\mathrm{C}=\mathrm{N}$ in amide (amide II).The bands at $1600 \mathrm{~cm}^{-1}$ and $1420 \mathrm{~cm}^{-1}$ were due to the $\mathrm{C}=\mathrm{C}$ stretching of aromatic rings. The peak at $1516 \mathrm{~cm}^{-1}$ was typical of an aromatic structure (e.g., lignin) ( $\mathrm{C}=\mathrm{C}$ stretching). The peak at $1456 \mathrm{~cm}^{-1}$ was attributed to $\mathrm{C}-\mathrm{H}$ bond deformation in aliphatic chains. The bands at $1273 \mathrm{~cm}^{-1}$ and $1215 \mathrm{~cm}^{-1}$ were due to $\mathrm{C}-\mathrm{O}$ bonds of phenol. The band at $1032 \mathrm{~cm}^{-1}$ was attributed to $\mathrm{C}-\mathrm{O}$ stretching in the polysaccharide, and the band at $840 \mathrm{~cm}^{-1}$ was due to $\mathrm{C}-\mathrm{H}$ deformation out of the plane (lignin structures).

${ }^{1} \mathrm{H}-\mathrm{NMR}$ spectra were recorded using a Bruker AC 300 spectrometer at $300 \mathrm{MHz}$ under homogated decoupling conditions, the HOD peak produced by water impurities and proton exchange being irradiated. The radio frequency level of HOD irradiation was optimized for each sample. The NMR samples were prepared by dissolving $10 \mathrm{mg}$ of sample in $0.5 \mathrm{~mL}$ solutions of $\mathrm{NaOD} 0.5 \mathrm{~mol} \mathrm{~L}^{-1}$. ${ }^{1} \mathrm{H}$-NMR gave semi-quantitative data, using calculations of the typical area corresponding to three regions. These regions were 0.5 to 3.3 ppm (alkyl protons, protons attached to carbon by an $\alpha$ bond to an aromatic ring or carboxylic groups, $\mathrm{H}_{\alpha}$ ), 4.8 to $3.3 \mathrm{ppm}$ (protons attached to carbon bearing oxygen or nitrogen), and 7.8 to $6.5 \mathrm{ppm}$ (aromatic and olefinic protons, $\mathrm{H}_{\mathrm{Ar}}$ ).

${ }^{13} \mathrm{C}$ NMR spectra were recorded using a Bruker AC 300 spectrometer at $75.43 \mathrm{MHz}$. The NMR samples were prepared by dissolving approximately $50 \mathrm{mg}$ of HA-like or unhydrolyzedalkali-soluble HA-like in $0.5 \mathrm{~mL}$ of $\mathrm{NaOD} 1.5 \mathrm{~mol} \mathrm{~L}^{-1}$. A quantitative intensity distribution was achieved by using the inversegated decoupling method: $0.23 \mathrm{~s}$ acquisition time, $45^{\circ}$ pulse, $2 \mathrm{~s}$ relaxation delay, line broadening at $20 \mathrm{~Hz}$, and a total acquisition time of $48 \mathrm{~h}$. All chemical shifts were quoted with reference to internal 4,4-dimetyl-4-silapentanesulfonic acid (Na-salt).

For a semi-quantitative approach, the ${ }^{13} \mathrm{C}-\mathrm{NMR}$ spectra were subdivided into six regions. The signals ranging between 190 and 165 ppm were attributed to carboxyl and amide carbons. Peaks between 165 and $145 \mathrm{ppm}$ arose from $\mathrm{C}=\mathrm{C}-\mathrm{O}$ of phenols. Peaks between 145 and $110 \mathrm{ppm}$ were due to aromatic 
carbons $(\mathrm{C}=\mathrm{C})$. The signals ranging between 110 and $60 \mathrm{ppm}$ were due to $\mathrm{C}-\mathrm{O}$ of carbohydrates and aliphatic alcohols. Peaks between 60 and $50 \mathrm{ppm}$ arose from methoxyl carbon $\left(\mathrm{O}-\mathrm{CH}_{3}\right)$. The signals ranging between 50 and $0 \mathrm{ppm}$ were due to alkyl carbons. Variations in $\mathrm{H}$ and $\mathrm{C}$ contents were calculated as [(starting content - final content)/starting content $] \times 100$.

\section{Results}

\section{Composting Process}

The decrease of volatile solids during composting indicated that degradation occurred during the whole composting process (Fig. 1). The composting process proceeded through the decomposition of the readily degradable organic fraction (cellulose, hemicellulose, proteins, and lipids; i.e., fraction I, II and III) (Almendros et al., 2000), whereas the lingo-humic complex (fraction IV) was concentrated, and, as expected, the ash content remained constant (Fig. 1). Composting was also found to affect the $\mathrm{C}$ fractions because these all decreased during composting (Table 1). In contrast, U-TOC was relatively stable during composting, decreasing by only $136 \mathrm{~g} \mathrm{~kg}^{-1}$ (Table 1). Because U-TOC represented the sum of all U-C fractions, the large decrease of the alkali-soluble fraction $(\mathrm{U}-\mathrm{TEC}=\mathrm{U}-\mathrm{HAC}+\mathrm{U}-$ $\mathrm{NHC}$ ) registered during composting could only be explained by an increase of the alkali-insoluble fraction (i.e., U-humin C) (Table 1). These data contrasted with our previous findings that indicated that during the composting process, soluble U-HA is formed from the insoluble U-HU (Genevini et al., 2003). A similar observation supporting our most recent findings has previously been reported (González-Vila et al., 1999). As demonstrated by our DRIFT spectra data (Fig. 2), composting also qualitatively modifies HA. When compared with HA extracted from FC and raw material (RM), the HA DRIFT spectra of EC indicated a decrease of aliphatic chains content and an increase of N-containing and lignin-derivates molecules (González-Vila et al., 1999). The increase of $\mathrm{N}$-molecules was most likely due to molecules of a microbial origin (González-Vila et al., 1999).

Purification of the parent material before HA extraction removed the HA labile fractions and simulated the biological process. This confirmed our previous findings (Chefetz et al., 1999; Genevini et al. 2002a, 2002b; Adani et al., 2006b) (i.e., a reduction of aliphatic chains and $\mathrm{N}$-containing molecules and an increase of lignin-derived molecules as revealed by the comparison of DRIFT spectra of HA and corresponding U-HA) (Fig. 2). The decrease of $\mathrm{N}$-molecules seems to confirm their microbial origin in HA because this fraction could only be removed by a chemical treatment. Also, it could not be removed during the biological process due to the presence of OMdegrading microorganisms that continually contributed through their biomass to enrich $\mathrm{HA}$ with $\mathrm{N}$-containing molecules (González-Vila et al., 1999).

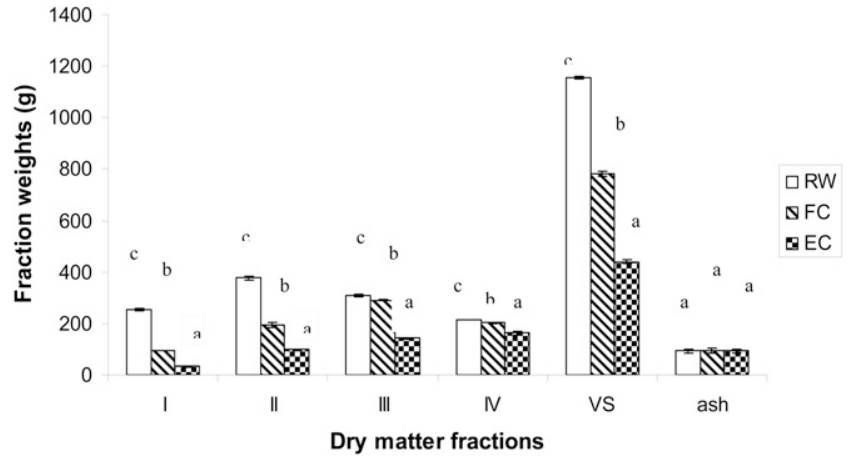

Fig. 1. Dry matter fractionation for raw material (RM), fresh compost (FC), and evolved compost (EC). I: fraction soluble in organic solvent; II: fraction soluble in $0.94 \mathrm{~mol} \mathrm{~L}^{-1} \mathrm{H}_{2} \mathrm{SO}_{4}$; III: fraction soluble in 13.50 $\mathrm{H}_{2} \mathrm{SO}_{4^{\prime}}$ IV: fraction insoluble in any solvent. VS: volatile solids.

Both ${ }^{1} \mathrm{H}-\mathrm{NMR}$ and ${ }^{13} \mathrm{C}-\mathrm{NMR}$ (Tables 2 and 3 ) confirmed what was previously known about the chemical modification of $\mathrm{HA}$ and U-HA during composting. The composting process of HA of RM compared with HA of EC found a decrease of the aliphatic proton content $(-21.7 \%)$ and an increase of the O/N-C$\mathrm{H}(+108 \%)$ and aromatic protons $(+160 \%)$ (Table 2). This trend was confirmed by ${ }^{13} \mathrm{C}-\mathrm{NMR}$, which revealed a relative decrease of alkyl-C content $(-62.2 \%)$ and an increase of carboxyl, phenol, aromatic, O-methoxyl, and O-alkyl carbons $(+20.9,+6.8,+11.5$, +45.8 , and $+11.4 \%$, respectively) in the HA fraction (comparing HA of RM vs. HA of EC) (Table 3) (Genevini et al., 2002a).

The chemical pretreatment of the raw material before HA extraction had similar effects on the composting process (Chefetz et al., 1999; Genevini et al., 2002a, 2002b). Our results demonstrate that the U-HA from RM was similar to HA extracted from EC, except for O-alkyl-C and alkyl-C, as shown by ${ }^{1} \mathrm{HNMR}$ and ${ }^{13} \mathrm{C}$-NMR (Tables 2 and 3). These differences could be due to the presence of acid-hydrolyzable $\mathrm{O} / \mathrm{N}$-alkyl-C and alkyl-C fractions in HA at the end of composting (EC-HA), which may be of microbial origin (González-Vila et al., 1999).

The biological process and the chemical treatments suggested that the origin of HA in compost throughout the biological degradation of the labile part of $\mathrm{HA}$ is due to the preservation of pre-existing recalcitrant fractions (e.g., U-HA) (Chefetz et

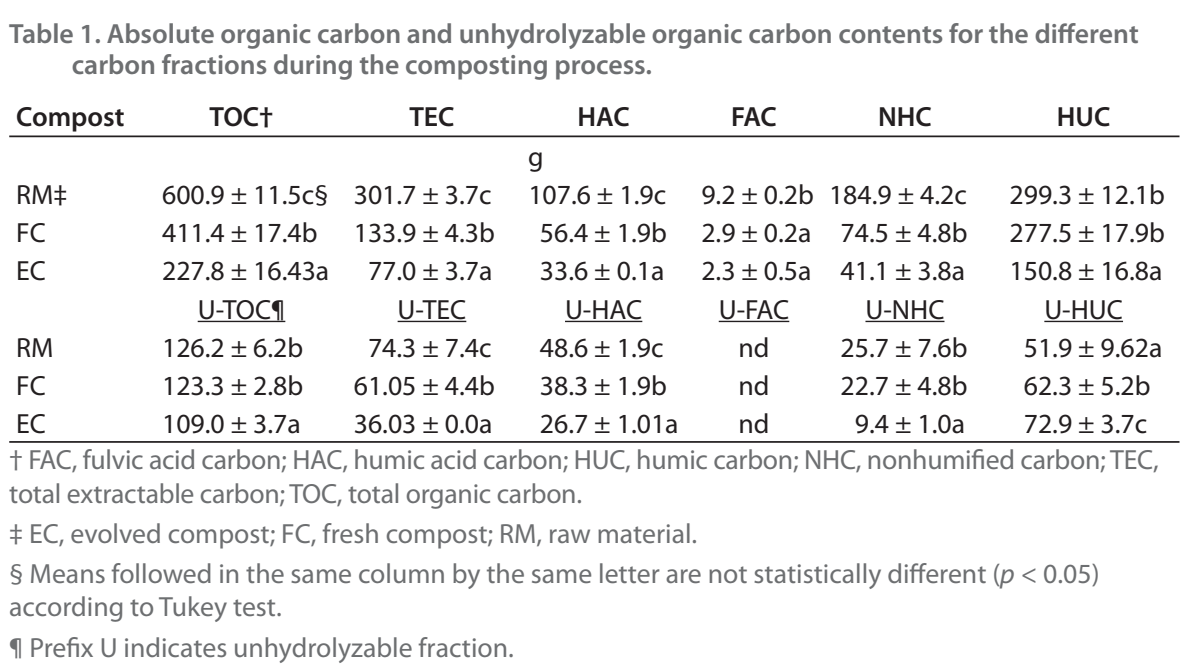

Table 1. Absolute organic carbon and unhydrolyzable organic carbon contents for the different

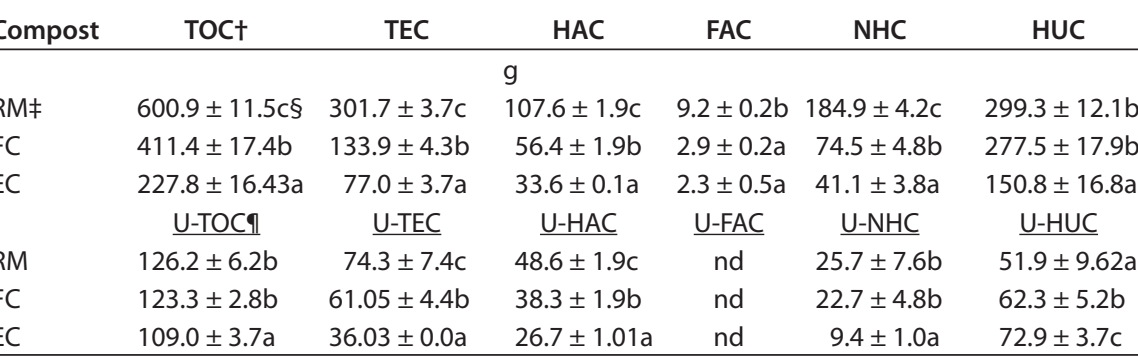
+ FAC, fulvic acid carbon; HAC, humic acid carbon; HUC, humic carbon; NHC, nonhumified carbon; TEC, total extractable carbon; TOC, total organic carbon.

$\S$ Means followed in the same column by the same letter are not statistically different $(p<0.05)$ ๆ Prefix U indicates unhydrolyzable fraction. 


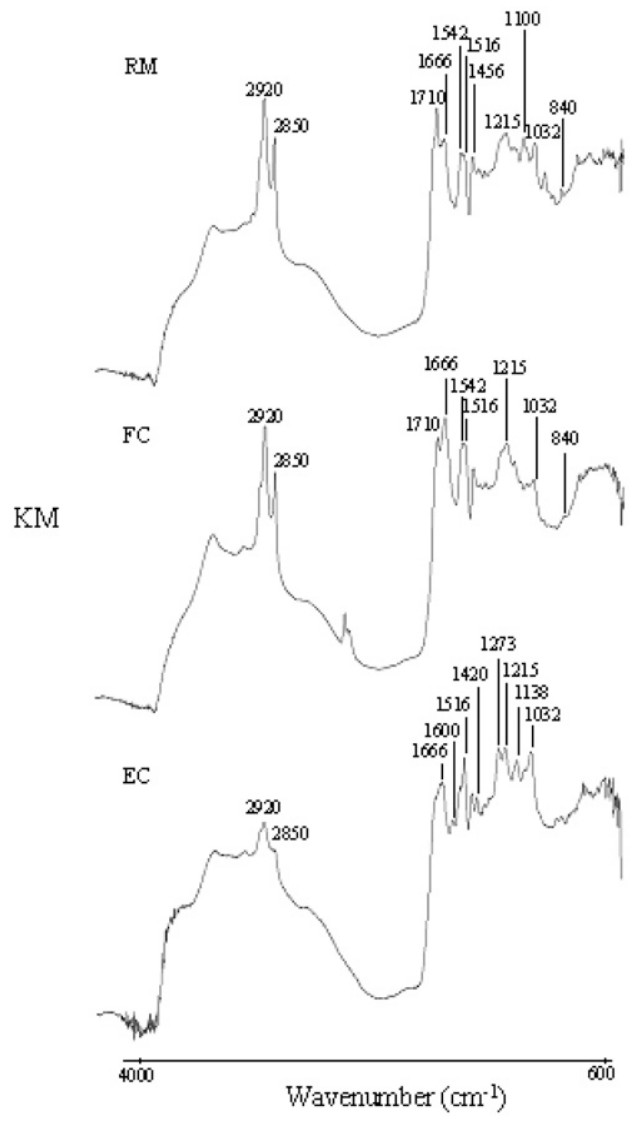

Fig. 2. DRIFT spectra for humic acids (left) and unhydrolyzable-humic acid (right) extracted from raw material (RM), fresh compost (FC), and evolved compost (EC).

Table 2. Integrated area (\%) of different hydrogen types of humic acid (HA) and unhydrolyzable humic acid (U-HA) extracted from compost at different stages, and incubated soil with composts at the start and end of the trials (' $\mathrm{H}$-nuclear magnetic resonance).

\begin{tabular}{lccc} 
Sample & $\begin{array}{c}\text { Aryl-H } \\
\text { (7.4-6.0 ppm) }\end{array}$ & $\begin{array}{c}\text { H-C-O } \\
\text { H-C-N } \\
(\mathbf{4 . 8 - 3 . 0 ~} \mathbf{~ p p m})\end{array}$ & $\begin{array}{c}\text { Alkyl-H } \\
(3.0-0.5 ~ p p m)\end{array}$ \\
\hline Composts & & & \\
HA-RM† & 5.8 & 8.6 & 85.6 \\
HA-FC & 4.8 & 4.6 & 90.5 \\
HA-EC & 15.1 & 17.9 & 67.0 \\
U-HA-FC & 18.0 & 23.2 & 58.7 \\
U-HA-RM & 14.8 & 23.5 & 61.7 \\
U-HA-EC & 28.8 & 32.8 & 38.3 \\
Soils & & & \\
HA-SRM§ T09 & 5.8 & 8.6 & 85.6 \\
HA-SRM T6 & 9.4 & 11.1 & 79.5 \\
HA-SFC T0 & 4.8 & 4.6 & 90.5 \\
HA-SFC T6 & 13.1 & 22.0 & 64.8 \\
HA-SEC T0 & 15.1 & 17.9 & 67.0 \\
HA-SEC T6 & 14.9 & 25.5 & 59.6 \\
U-HA-SRM T0 & 14.8 & 23.5 & 61.7 \\
U-HA-SRM T6 & 19.9 & 25.6 & 54.5 \\
U-HA-SFC T0 & 18.0 & 23.3 & 58.7 \\
U HA-SFC T6 & 18.4 & 29.7 & 51.8 \\
U-HA-SEC T0 & 28.8 & 32.9 & 38.3 \\
U-HA-SEC T6 & 23.1 & 27.2 & 49.6 \\
\hline
\end{tabular}

† RM, raw material; $\mathrm{FC}$, fresh compost; EC, evolved compost.

‡ Prefix U indicates unhydrolyzable fraction.

$\S$ Soil incubated with: raw material (SRM), fresh compost (SFC), and evolved compost (SEC).

ๆ T0, T6: soil sampled after 0 and 6 mo of incubation. al., 1999). Unhydrolyzable HA extracted from the final stage of composting (U-HA from EC) was more aromatic and less aliphatic than U-HA from RM and FC (Table 3), indicating that U-HA was modified during composting. From ${ }^{13} \mathrm{C}-\mathrm{NMR}$ it can be seen that this modification was due to the loss of the major part of the alkyl-C (a decrease of 56\%), passing from RM to EC. This was confirmed by calculating the absolute content of the different $\mathrm{C}$-types by using data reported in Table 3 and Table 1. From this calculation it could be shown that alkyl-C accounted for more than $50 \%$ of the total C loss, followed by an aryl-C loss of $16.7 \%$, a carboxyl-C loss of $16.3 \%$, an O-methoxyl-C loss of $10.2 \%$, and a N/O-alkyl-C loss of 3.4\%. Phenol-C remained unchanged.

Consequently, the relative concentrations of phenol and aryl-C increased by $79.7 \%$ and $34.7 \%$, respectively. This trend was further confirmed by the good correlation found between aryl-C and phenol-C vs. alkyl-C (alkyl-C vs. aryl-C: $r=-0.99, P<0.01$; alkyl$\mathrm{C}$ vs. phenol-C: $r=-0.97, P<0.01)$. These results suggest that a fraction formed mainly by the alkyl-C of the U-HA becomes more hydrolyzable as the biological process (composting) proceeds. The loss of this fraction from the U-HAC could also explain the decrease of U-HAC content in EC as previously shown by mass balance (Table 1).

\section{Soil Incubation}

As a consequence of microbial activity, soil incubated with raw material (SRM) exhibited a TOC decrease after 6 mo of incubation (Fig. 3). A general decrease of all $\mathrm{C}$ fractions composing the TOC occurred during the incubation (Fig. 3). In particular, TEC, HAC, FAC, NHC, and HUC decreased by 622, 707, 807, 577 , and $497 \mathrm{~g} \mathrm{~kg}^{-1}$, respectively. In contrast, recalcitrant carbon (UTOC) remained relatively constant during the 6-mo incubation period (Table 4). This is important because it justifies the approach used in this experiment whereby we added an equal amount of U-TOC (the stable fraction of carbon over a medium-term incubation period), independent of the degree of compost evolution (Adani and Ricca, 2004), to each sample. We noted deceases in U-TEC, U-HAC, and U-NHC of 581,607 , and $539 \mathrm{~g} \mathrm{~kg}^{-1}$, respectively, whereas U-HUC increased by $745 \mathrm{~g} \mathrm{~kg}^{-1}$.

Soil amended with fresh compost exhibited a similar trend to SRM (Fig. 3) in that all carbon fractions decreased during incubation, but less than was the case in the other samples. 
Table 3. Integrated area (\%) of different carbon types of humic acid (HA) and unhydrolyzable humic acid (U-HA) extracted from compost at different stages and incubated soil with composts at the start and end of the trials $\left({ }^{13} \mathrm{C}\right.$-nuclear magnetic resonance).

\begin{tabular}{|c|c|c|c|c|c|c|}
\hline Sample & $\begin{array}{c}\text { Carboxyl-C } \\
(190-165 \text { ppm) }\end{array}$ & $\begin{array}{c}\text { Phenol-C } \\
\text { (165-145 ppm) }\end{array}$ & $\begin{array}{c}\text { Aryl-C } \\
(145-110 \text { ppm) }\end{array}$ & $\begin{array}{c}\text { O-alkyl-C } \\
(110-60 \text { ppm) }\end{array}$ & $\begin{array}{l}\text { O-methoxyl-C } \\
\text { (60-50 ppm) }\end{array}$ & $\begin{array}{c}\text { Alkyl-C } \\
\text { (50-0 ppm) }\end{array}$ \\
\hline \multicolumn{7}{|l|}{ Composts } \\
\hline HA-RM† & 9.8 & 3.3 & 16.5 & 5.9 & 7.2 & 57.2 \\
\hline $\mathrm{HA}-\mathrm{FC}$ & 11.9 & 3.9 & 14.2 & 12.2 & 7.3 & 50.5 \\
\hline HA-EC & 12.4 & 10.1 & 28.0 & 17.3 & 10.5 & 21.6 \\
\hline U-HA-RM‡ & 14.6 & 8.9 & 29.4 & 5.1 & 10.6 & 31.3 \\
\hline U-HA-FC & 10.9 & 9.6 & 32.3 & 10.4 & 11.7 & 25.1 \\
\hline U-HA-EC & 13.0 & 16.0 & 39.6 & 6.4 & 10.9 & 13.8 \\
\hline \multicolumn{7}{|l|}{ Soils } \\
\hline HA-SRM§ TOף & 9.8 & 3.3 & 16.5 & 5.9 & 7.2 & 57.2 \\
\hline HA-SRM T6 & 20.4 & 3.3 & 23.6 & 20.0 & 8.0 & 24.6 \\
\hline HA-SFC TO & 11.9 & 3.9 & 14.2 & 12.2 & 7.3 & 50.5 \\
\hline HA-SFC T6 & 12.8 & 5.7 & 19.9 & 19.3 & 11.6 & 30.7 \\
\hline HA-SEC TO & 12.4 & 10.1 & 28.0 & 17.3 & 10.5 & 21.6 \\
\hline HA-SEC T6 & 18.8 & 11.4 & 22.3 & 23.7 & 7.0 & 16.7 \\
\hline U-HA-SRM TO & 14.6 & 8.9 & 29.4 & 5.1 & 10.6 & 31.3 \\
\hline U-HA-SRM T6 & 14.0 & 13.3 & 32.6 & 8.8 & 12.8 & 18.4 \\
\hline U-HA-SFC TO & 10.9 & 9.6 & 32.3 & 10.4 & 11.7 & 25.1 \\
\hline U-HA-SFC T6 & 10.9 & 13.6 & 36.8 & 5.1 & 14.1 & 19.3 \\
\hline U-HA-SCE TO & 13.0 & 16.0 & 39.6 & 6.4 & 10.9 & 13.8 \\
\hline U-HA-SCE T6 & 13.9 & 16.8 & 41.1 & 2.3 & 12.2 & 13.6 \\
\hline
\end{tabular}

† EC, evolved compost; FC, fresh compost; RM, raw material.

₹ Prefix U indicates unhydrolyzable fraction.

$\S$ Soil incubated with raw material (SRM), fresh compost (SFC), and evolved compost (SEC).

ๆ T0, T6: soil sampled after 0 and 6 mo of incubation.

Total organic carbon decreased by $484 \mathrm{~g} \mathrm{~kg}^{-1}$, whereas TEC, HAC, FAC, NHC, and HUC decreased by 689, 577, 608, 373 , and $358 \mathrm{~g} \mathrm{~kg}^{-1}$, respectively. Unhydrolyzable TOC remained constant during the 6-mo incubation period (Table 4). In contrast, U-TEC, U- HAC, and U-NHC decreased by 611,590 , and $645 \mathrm{~g} \mathrm{~kg}^{-1}$, respectively, whereas U-HUC increased by $471 \mathrm{~g} \mathrm{~kg}^{-1}$ (Table 4).

Soil amended with EC showed a different trend with respect to SRM and SFC. Carbon fractions decreased, but this decrease was less pronounced than observed in SFC and SRM. Total organic carbon, TEC, HAC, and HUC decreased by 276, 55, 560, and $335 \mathrm{~g} \mathrm{~kg}^{-1}$, respectively (Fig. 3), whereas NHC increased by $302 \mathrm{~g} \mathrm{~kg}^{-1}$ (Fig. 3). Unlike the other two samples, UTOC decreased significantly $\left(-211 \mathrm{~g} \mathrm{~kg}^{-1}\right)$. Similarly, U-TEC and U-HAC decreased significantly by 351 and $500 \mathrm{~g} \mathrm{~kg}^{-1}$, respectively, whereas U-NHC increased $\left(428 \mathrm{~g} \mathrm{~kg}^{-1}\right)$ (Table 4).

After 6 mo of incubation of the amendments in artificial soils (sample T6), HA composition exhibited a modified DRIFT spectrum (Fig. 4). This indicated that incubation removed the labile fraction (i.e., lipids from HA for SRM and SFC and concentrated $\mathrm{N}$-containing and lignin-derived molecules). In contrast, the DRIFT spectrum of HA extracted from the EC-amended soils (SEC) after 6 mo of incubation did not show an appreciable difference to that of HA extracted at time zero (T0).

These observations were confirmed by ${ }^{1} \mathrm{H}-\mathrm{NMR}$ and ${ }^{13} \mathrm{C}$ NMR spectra of HA that changed significantly for SRM and SFC after 6 mo of incubation. The alkyl fraction decreased, and the $\mathrm{O} / \mathrm{N}$-alkyl and aryl/phenol fractions increased (Tables 2 and 3). On the other hand, SEC did not exhibit much variation (Table 3).

As demonstrated by the composting process and the DRIFT spectra (Fig. 4), chemical pretreatment of soils before HA ex- traction had an effect similar to biological processes (Fig. 3). The NMR data demonstrated that during composting of SRM and SFC, the alkyl fraction became more hydrolyzable, and phenol-C increased with prolonged incubation times (Table 3).

\section{Discussion}

Degradation processes during composting affect the HA content and its quality. The HA content decreases due to the degradation of labile organic molecules forming more recalcitrant (i.e., the unhydrolyzable) HAs (Chefetz et al., 1999). Therefore, HAs were formed by a labile fraction and a recalcitrant fraction that was preserved (Binachessi da Chuna-Santino and Bianchini Júnior, 2002). We have found that HA from more evolved compost contains more recalcitrant fraction (aromatic carbon) and less labile fraction (aliphatic carbon) than HA from RM and FC, indicating that HA composition is dependant on the composting duration.

Labile fractions consist of a free and a hydrolyzable-lipid fraction (free fatty acids and esterifies lipids) that account for approximately $67 \%\left({ }^{13} \mathrm{C}-\mathrm{NMR}\right.$ data) of total HA lost during composting (Genevini et al., 2002a). O/N-alkyl C contributed modestly to the composition of the labile fraction as its content increased during composting (see ${ }^{13} \mathrm{C}-\mathrm{NMR}$ data in the Results section). The degradation of HA-carbohydrates during composting is well documented in the literature (González-Vila et al., 1999; Almendros and Dorado, 1999). It is likely that the O/N-alkyl fraction of HA, for example the carbohydrates and proteins that are hydrolyzable, also contribute to the labile-HA fraction. However, this fact was probably masked by the production of newly formed alkali-soluble molecules of microbial origin that contributed to HA molecules (González-Vila et al., 1999). In addition, the strong decrease of the alkyl fraction determining a strong relative increase of the other 

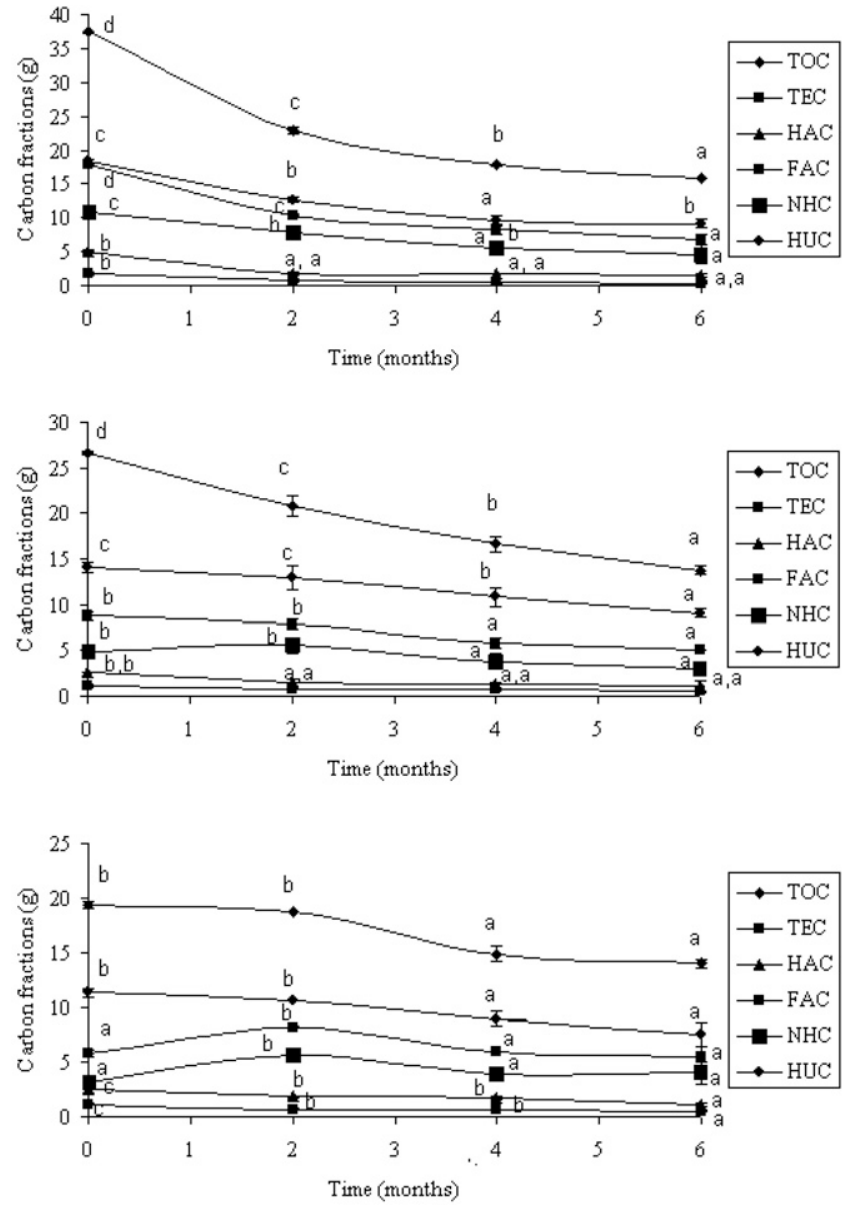

Fig. 3. Absolute organic carbon and unhydrolyzable-carbon fraction contents during incubation of composts in soils. Soil amended with raw material (top); soil amended with fresh compost (middle); soil amended with evolved compost (bottom). FAC, fulvic acid carbon; HAC, humic acid carbon; HUC, humic carbon; NHC, nonhumified carbon; TEC, total extractable carbon; TOC, total organic carbon.

fractions may have contributed to this apparent nondegradation of the $\mathrm{O} / \mathrm{N}$-alkyl fraction. This may have also occurred for the aromatic fraction (aryl-C + Phenol-C) but is unlikely because the increase of this fraction was double that of O-alkyl-C, indicating a degradation of recalcitrant fraction.

Table 4. Unhydrolyzable organic carbon contents during incubation trials.

\begin{tabular}{lllrcrc} 
Sample & & Ut-TOC $\neq$ & U-TEC & U-HAC & U-NHC & U-HUC \\
\hline \multirow{2}{*}{ SRM§ } & T0ף & $7.30 \pm 0.55 \mathrm{a} \#$ & $4.35 \pm 0.27 \mathrm{~b}$ & $3.12 \pm 0.22 \mathrm{~b}$ & $1.52 \pm 0.34 \mathrm{~b}$ & $2.95 \pm 0.60 \mathrm{a}$ \\
& T6 & $6.97 \pm 0.75 \mathrm{a}$ & $1.82 \pm 0.37 \mathrm{a}$ & $1.12 \pm 0.3 \mathrm{a}$ & $0.7 \pm 0.47 \mathrm{a}$ & $5.15 \pm 0.82 \mathrm{~b}$ \\
SFC & T0 & $7.25 \pm 0.05 \mathrm{a}$ & $3.6 \pm 0.36 \mathrm{~b}$ & $2.32 \pm 0.57 \mathrm{~b}$ & $1.27 \pm 0.58 \mathrm{~b}$ & $3.65 \pm 0.36 \mathrm{a}$ \\
& T6 & $6.77 \pm 0.62 \mathrm{a}$ & $1.4 \pm 0.13 \mathrm{a}$ & $0.95 \pm 0.20 \mathrm{a}$ & $0.45 \pm 0.32 \mathrm{a}$ & $5.37 \pm 0.62 \mathrm{~b}$ \\
SEC & T0 & $7.57 \pm 0.32 \mathrm{~b}$ & $2.7 \pm 0.30 \mathrm{~b}$ & $2 \pm 0.25 \mathrm{~b}$ & $0.7 \pm 0.40 \mathrm{a}$ & $4.87 \pm 0.45 \mathrm{a}$ \\
& T6 & $5.97 \pm 0.50 \mathrm{a}$ & $1.75 \pm 0.30 \mathrm{a}$ & $1 \pm 0.22 \mathrm{a}$ & $1 \pm 0.37 \mathrm{~b}$ & $4.22 \pm 0.30 \mathrm{a}$ \\
\hline
\end{tabular}

† Prefix U indicates unhydrolyzable fraction.

₹ FAC, fulvic acid carbon; HAC, humic acid carbon; HUC, humic carbon; NHC,

nonhumified carbon; TEC, total extractable carbon; TOC, total organic carbon.

$\S$ Soil incubated with raw material (SRM), fresh compost (SFC), and evolved compost (SEC). १ T0, T6: soil sampled after 0 and 6 mo of incubation.

\# Means followed in the same column by the same letter are not statistically different $(p<0.05)$ according to Tukey test.
The unhydrolyzable recalcitrant fraction of HA, the U-HA, is mainly composed of highly polymerized aromatic lignin-derived molecules (acid-resistant lignin) (Leary et al., 1986) and carbohydrates (Kniker and Lüdemam, 1995), probably forming an unhydrolyzable cross-linked network (e.g., alkali soluble part of the cell wall of plant material) (Adani and Ricca, 2004; Adani et al., 2006c; Adani et al., 2007). The U-HA was not stable during the composting processes. Our results suggested that the alkyl fraction contributed above all to the loss of the U-HA. This fact contributed to the relative increase of the aromatic- $\mathrm{C}$ content of the U-HA.

Composts in soils were degraded at a rate depending on their degree of evolution (Pascual et al., 1999), as RM was degraded to a greater extent than EC. The use of fresh material allowed for higher TOC and, more significantly, higher U-TOC contents at the end of the incubation. These data are not surprising because TOC dosed with RM and FC was much higher than that dosed with EC. On the other hand, the U-TOC results are unexpected because it was dosed with the same amount for the different samples. This suggested that the biological stability of the biochemically protected carbon (the U-TOC) depended on the amount of available- $\mathrm{C}$ for microorganisms. Therefore, the higher amounts of labile-C from samples with RM and FC allowed for the preservation of the more stable-C.

Humic acids were degraded at different rates depending on their content in the labile fractions (Almendros and Dorado, 1999). As composting removed the HA labile fraction, HA from EC showed the lowest rate of degradation when incubated in soil. Nevertheless, because of the higher level of HA dosed, soil amended with RM showed a higher HA content at the end of the incubation period. However, the final content of HA from FC and EC was similar. Humic acid degradation of SFC proceeded mainly by degradation of the alkyl fraction, whereas for SEC, the aromatic fraction was mainly degraded.

When the U-HA was considered, the two samples showed interesting results. Although at the end of the incubation period U-HA contents were the same, the joint decrease of U-HA and U-TOC registered for SEC suggested that U-HA was probably degraded. In contrast, SFC showed constant U-TOC values, suggesting that the U-HA fraction was not degraded but probably was insolubilized.

Humic acid from EC was expected to be more recalcitrant to degradation. However, we found that a prolonged stabilization/humification process influenced its degradability, as confirmed by the reduced presence of the labile fraction with respect to the other samples. Although this in itself is not a new finding because it was previously shown that HAs were less degraded when copious nutrients were present in the system (Filip and Kubát, 2001; Filip and Tesařová, 2004), the common belief has been that compost should be obtained after long composting periods because the formation of evolved humified material takes a long time (Chen and Inbar, 1993). However, our results indicate that the contribution of compost to soil humus depends on the compost U-HA content and on the presence of the labile fraction that is able to modulate 

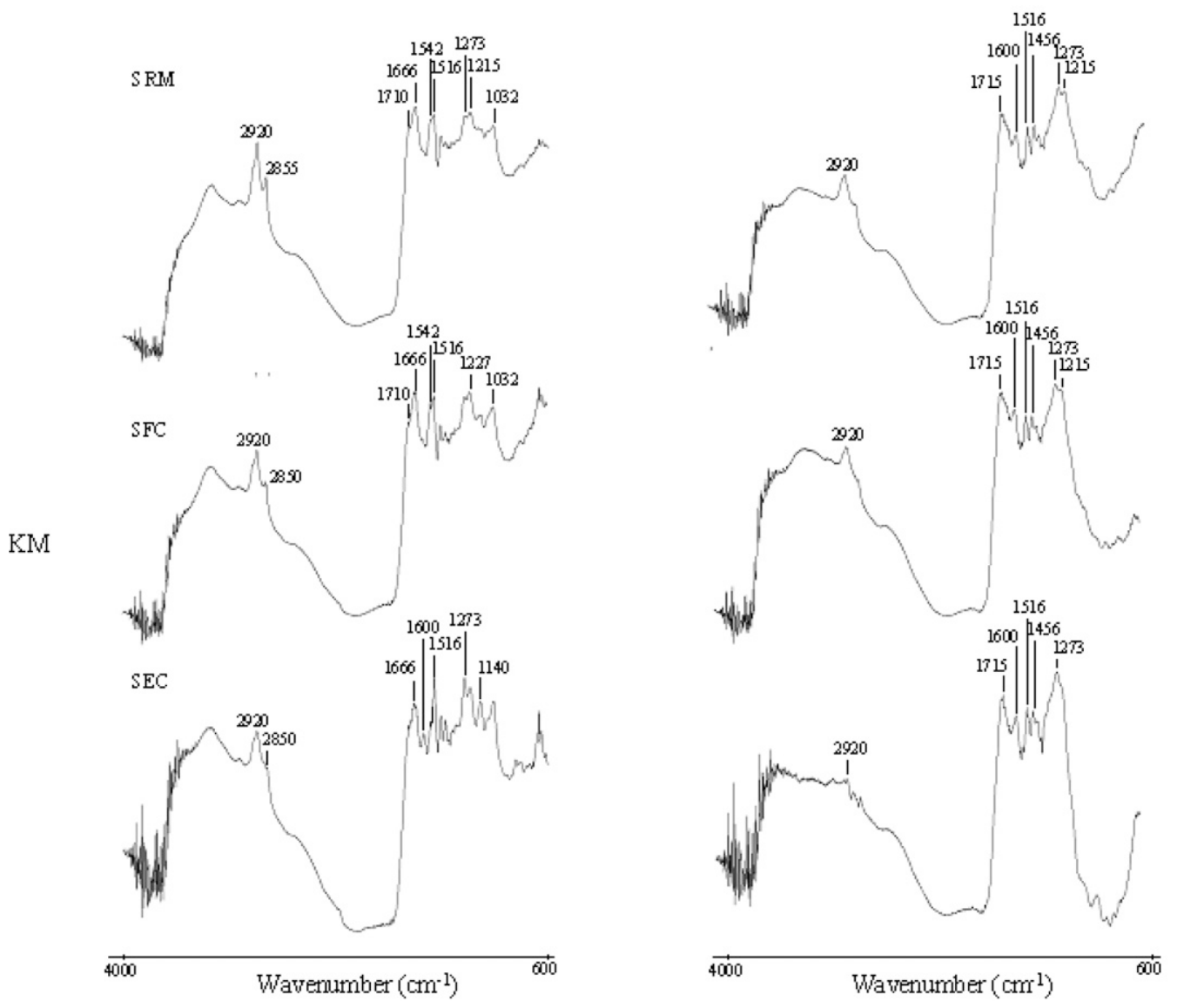

Fig. 4. Diffuse reflectance infrared fourier transformed spectra for humic acids (left) and unhydrolyzable-humic acid (right) extracted from soils incubated with raw material (SRM), fresh compost (SFC), and evolved compost (SEC) after 6 mo of incubation.

the preservation of the recalcitrant fraction. Therefore, RM and FC contribute to soil humus better than EC due to the presence of the labile fraction. In addition, the labile fraction plays an important role in soil structure formation and as nutrient (Swift, 1991).

\section{References}

Adani, F., R. Confalonieri, and F. Tambone. 2004. Dynamic respiration index as descriptor of the biological stability of organic wastes. J. Environ. Qual. 33:1866-1876.

Adani, F., P.L. Genevini, F. Gasperi, and F. Tambone. 1999. Composting and humification. Compost Sci. Util. 7:24-33.

Adani, F., P.L. Genevini, F. Tambone, and E. Montoneri. 2006a. Compost effect on soil humic acid: A NMR study. Chemosphere 65:1414-1418.

Adani, F., and G. Ricca. 2004. The contribution of alkali soluble (humic acid-like) and unhydrolyzed-alkali soluble (core-humic acid-like) fractions extracted from maize plant to the formation of soil humic acid. Chemosphere 56:13-22.

Adani, F., G. Ricca, F. Tambone, and P.L. Genevini. 2006b. The isolation of the stable fraction (the core) of the humic acid. Chemosphere 65:1300-1307.

Adani, F., M. Spagnol, and P.L. Genevini. 2006c. Biochemical origin and refractory properties of humic acid extracted from the maize plant. Biogeochemistry 78:85-96.

Adani, F., M. Spagnol, and K. Nierop. 2007. Biochemical origin and refractory properties of humic acid extracted from maize plants: The contribution of lignin. Biogeochemistry 82:55-65.

Almendros, G., and J. Dorado. 1999. Molecular characteristics related to the biodegradability of humic acid preparation. Eur. J. Soil Sci. 50:227-236.

Almendros, G., J. Dorado, F.J. González-Vila, M.J. Blanco, and U. Lankes. 2000. ${ }^{13} \mathrm{C}$ NMR assessment of decomposition patterns during composting of forest and shrub biomass. Soil Biol. Biochem. 32:793-804.

APHA. 1992. Standard methods for examination of water and wastewater. 18th ed. Part 2540D. American Public Health Assoc., Washington, DC.

Binachessi da Chuna-Santino, M., and I. Bianchini Júnior. 2002. Humic substance mineralization in a tropical oxbow lake (São Paulo, Brazil). Hydrobiologia 468:33-43.

Chefetz, B., F. Adani, P.L. Genevini, Y. Hadar, F. Tambone, and Y. Chen. 1999. Humic-acid transformation during composting of municipal solid waste. J. Environ. Qual. 27:794-800.

Chen, Y., and Y. Inbar. 1993. Chemical and spectroscopical analyses of organic matter transformation during composting in relation to compost maturity. p. 551-600. In HAJ Hoitink and H.M. Keener (ed.) Science and engineering of composting: Design, environmental, microbiology and utilization aspects. The Ohio State Univ., Wooster, OH.

Ciavatta, C., M. Govi, A.L. Vittori, and P. Sequi. 1990. Determination of organic carbon in soil and fertilizers. Commun. Soil Sci. Plant Anal. 20:759-773.

Filip, Z., and J. Kubát. 2001. Microbial utilization and transformation of humic substances extracted from soils of long-term field experiments. Eur. J. Soil Biol. 37:167-174.

Filip, Z., and M. Tesařová. 2004. Microbial degradation and transformation of humic acids from permanent meadow and forest soils. Int. Biodeterior. Biodegrad. 54:225-231.

Genevini, P.L., F. Adani, A.H.M. Veeken, K.G.J. Nierop, B. Scaglia, and C. Dijkema. 2002a. Qualitative modification of humic acid and corehumic acid during high-rate composting of pig faeces amended with wheat straw. Soil Sci. Plant Nutr. 48:135-141.

Genevini, P.L., F. Adani, A.H.M. Veeken, and B. Scaglia. 2002b. Evolution of humic and core-humic during high-rate composting of pig faeces amended with wheat straw. Soil Sci. Plant Nutr. 48:143-150.

Genevini, P.L., F. Tambone, F. Adani, H.M. Veeken, K.G.J. Nierop, and E. Montoneri. 2003. Evolution and qualitative modifications of huminlike matter during high rate composting of pig feces amended with 
wheat straw. Soil Sci. Plant Nutr. 49:785-792.

Giusquiani, P.L., M. Pagliai, G. Gigliotti, D. Businelli, and A. Benetti. 1995. Urban waste compost: Effects on physical, chemical, and biochemical soil properties. J. Environ. Qual. 24:175-182.

González-Vila, F.J., G. Almendros, and F. Madrid. 1999. Molecular alteration of organic fraction from urban waste in the course of composting and their further transformation in amended soil. Sci. Total Environ. 236:215-229.

Inbar, Y., Y. Chen, and Y. Hadar. 1990. Humic substances formed during the composting of organic matter. Soil Sci. Soc. Am. J. 54:1316-1323.

Kniker, H., and P. Lüdemam. 1995. N-15 and C-13 CPMAS and solution NMR studies of N-15 enriched plant material during 600 days of microbial degradation. Org. Geochem. 23:329-341.

Lal, R. 2000. World cropland soils as a source or sink for atmospheric carbon. Adv. Agron. 71:145-191.

Leary, G.J., R.H. Newman, and K.R. Morgan. 1986. A carbon-13 nuclear resonance study of chemical processes involved in the isolation of Klason lignin. Holzforschung 40:267-272.

Leifeld, J., S. Siebert, and I. Kogel-Knaber. 2002. Changes in the chemical composition of soil organic matter after application of compost. Eur. J. Soil Sci. 53:299-309.

Mikutta, R., M. Kleber, M.S. Torn, and R. Jahn. 2006. Stabilization of soil organic matter: Association with minerals or chemical recalcitrance? Biogeochemistry 77:25-56.

Pascual, J.A., C. Garćia, and T. Hernandez. 1999. Comparison of fresh and composted organic wastes in their efficacy for the improvement of arid soil. Bioresour. Technol. 68:255-264.

Piccolo, A. 2002. The supramolecular structure of humic substances: A novel understanding of humus chemistry and implications in soil science. Adv. Agron. 75:58-134.

Qualls, R.G. 2004. Biodegradability of humic substances and other fractions of decomposing leaf litter. Soil Sci. Soc. Am. J. 68:1705-1712.

Quèdraogo, E., A. Mando, and N.P. Zombrè. 2001. Use of compost to improve soil properties and crop productivity under low input agricultural system in West Africa. Agric. Ecosyst. Environ. 84:259-266.

Scaglia, B., F. Tambone, P.L. Genevini, and F. Adani. 2000. New rules for the design of composting plants and compost quality in the Regione Lombardia (North Italy). BioCycle 4:80-82.

Senesi, N., and E. Loffredo. 1999. The chemistry of soil organic matter. p. 239-370. In D.L. Sparks (ed.) Soil physical chemistry. CRC Press, New York.

Simpson, A.J. 2002. Determining the molecular weight, aggregation, structures, and interaction of natural organic matter using diffusion ordered spectroscopy. Magn. Reson. Chem. 40:S72-S82.

Six, J., R.T. Conant, E.A. Paul, and E.A.P. Paustian. 2002. Stabilization mechanism of soil organic matter: Implication for C-saturation of soil. Plant Soil 241:155-176.

Sugahara, K., and A. Inoko. 1981. Composition analysis of humus and characterization of humic acid obtained from city refuse compost. Soil Sci. Plant Nutr. 41:753-761.

Sutton, R., and G. Sposito. 2005. Molecular structure in soil humic substances: The new view. Environ. Sci. Technol. 39:9009-9015.

Swift, R.S. 1991 Effects of humic substances and polysaccharides on soil aggregation. p. 153-162. In W.S. Wilson (ed.) Advances in soil organic matter research: The impact on agriculture and the environment. The proceedings of a joint symposium held at University of Essex, 3-4 Sept. 1990. Special Publ. no. 90. The Royal Society of Chemistry, Cambridge.

U.S. Composting Council. 1997. Field sampling of compost materials (06.01). In P.B. Leege and W.H. Thompson (ed.) Test methods for the examination of composting and compost. U.S. Composting Council, Bethesda, MD. 